\title{
Experiment and simulation on air layer drag reduction of high-speed underwater axisymmetric projectile
}

\author{
Xianxian Yu ${ }^{a}$, Yiwei Wang ${ }^{\mathrm{a}, *}$, Chenguang Huang ${ }^{\mathrm{a}}$, Yanpeng Wei ${ }^{\mathrm{a}}$, Xin Fang ${ }^{\mathrm{b}}$, \\ Tezhuan $\mathrm{Du}^{\mathrm{a}}$, Xiaocui $\mathrm{Wu}^{\mathrm{a}}$ \\ ${ }^{a}$ Key Laboratory for Mechanics in Fluid Solid Coupling Systems, Institute of Mechanics, Chinese Academy of Sciences, Beijing, 100190, China \\ ${ }^{\mathrm{b}}$ The State Key Laboratory of Nonlinear Mechanics, Institute of Mechanics, Chinese Academy of Sciences, Beijing, 100190, China
}

\section{H I G H L I G H T S}

- Experiment and simulation are both taken on axisymmetric body.

- Mechanism of drag reduction is analyzed.

- Unsteady evolution of drag is investigated.

\section{A R T I C L E I N F O}

\section{Article history:}

Received 27 April 2014

Received in revised form

1 December 2014

Accepted 8 January 2015

Available online 11 February 2015

\section{Keywords:}

Axisymmetric projectile

Air layer

Boundary layer

Drag reduction

\section{G R A P H I C A L A B S T R A C T}

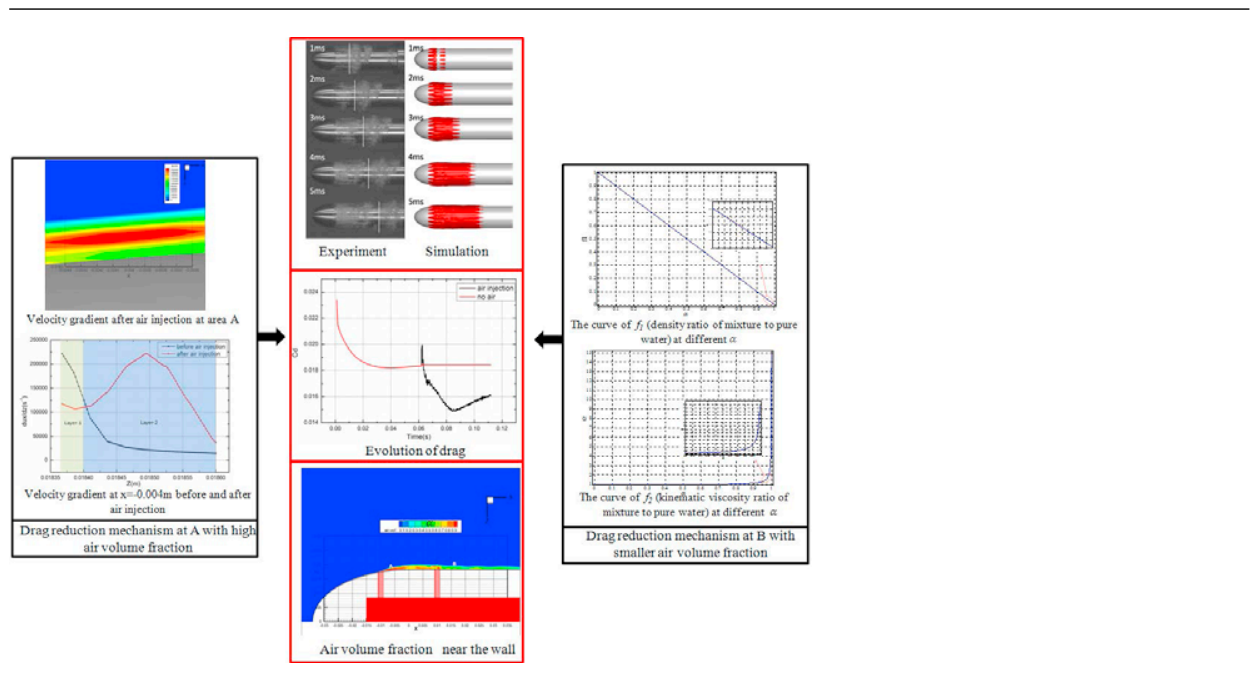

\section{A B S T R A C T}

Injection of air could lead to creation of a bubbly mixture or air layer near the surface that can significantly adjust the flow within the turbulent boundary layer. In this paper, stress wave propagation techniques and Split Hopkinson Pressure Bar (SHPB) are used in underwater launching experiment. Simulation with volume of fluid (VOF) method and modified renormalization group (RNG) k- $\varepsilon$ model is also performed to study the physical process of drag reduction of axisymmetric body. Comparison between numerical and experimental air layer length shows good correlation. Results indicate that air layer has good effect on drag reduction. Friction drag reduction mechanism is analyzed from two aspects due to different air volume fraction $\alpha$. At area with high $\alpha$, fluid is heterogeneous and layered. Drag reduction is from decrease of velocity gradient and dynamic viscosity at the wall. At area with small $\alpha$, the mixture is homogeneous. Empirical equation of turbulent boundary layer shear stress is applied to describe drag reduction mechanism. The unsteady evolution of drag with injection of air is also studied at last.

(c) 2015 Elsevier Masson SAS. All rights reserved.

\footnotetext{
* Corresponding author.
}

E-mail address: wangyw@imech.ac.cn (Y. Wang). 


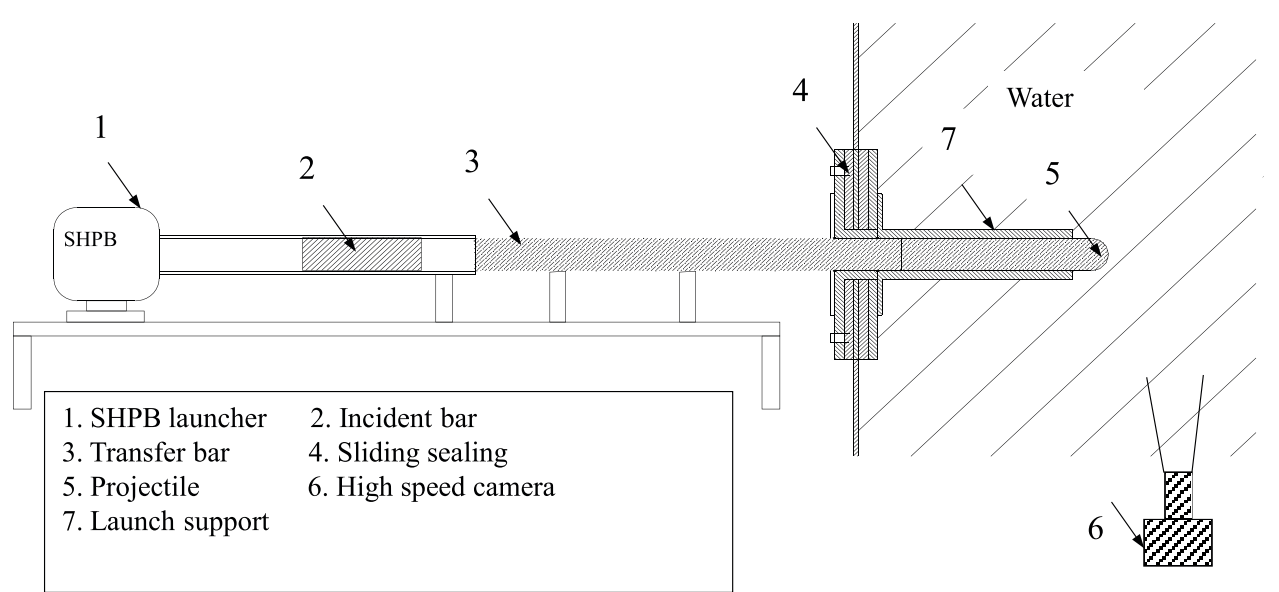

Fig. 1. Underwater launching system.

\section{Introduction}

Skin-friction drag constitutes a significant portion of the total resistance for nearly all transportation systems moving in a fluid [1]. Turbulent boundary layer skin friction in liquid flows may be reduced when bubbles or air layer is formed near the surface. The lubrication of external liquid flow with a bubbly mixture or air layer has been the goal of engineers for many years. This phenomenon was first detected by McCormick and Bhattacharyya [2], who found that viscous drag reduction of a fully-submerged body of revolution is obtained by creating hydrogen gas on the hull.

Merkle et al. [3-5] did much research on microbubble drag reduction through both experiment and simulation. In their research, integrated skin friction reduction of greater than $80 \%$ is observed. The volumetric gas flow required for this maximum is nominally equal to the volume flow of liquid in the boundary layer. In their simulation, a well-tested boundary-layer code employing a simple mixing length model for the turbulence is used. The order of magnitude and trends of the experimental skin-friction reduction are reproduced quite well by this simple model. Elbing et al. $[1,6-8]$ did a set of experiments to investigate the phenomena of skin-friction drag reduction in a turbulent boundary layer (TBL) at large scales and high Reynolds numbers. Two distinct dragreduction phenomena were investigated: bubble drag reduction (BDR) and air-layer drag reduction (ALDR). Results from the BDR experiments indicate that significant drag reduction $(>25 \%)$ is limited to the first few meters downstream of injection. Once ALDR was established, friction drag reduction in excess of $80 \%$ was observed. They also found the critical air flux required to establish ALDR. Xu et al. [9] report a series of numerical simulation of small bubbles seeded in a turbulent channel flow at average volume fraction of up to $8 \%$. These results show that even for relatively large bubbles, an initial transient drag reduction can occur as bubbles disperse into the flow. Relatively small spherical bubbles will produce a sustained level of drag reduction over time. Sanders et al. [10] studied the bubble friction drag reduction in highReynolds-number (210 million) flat-plate turbulent boundary layer. Buoyancy pushed the air bubbles to the plate surface where they coalesced to form a nearly continuous gas film that persisted to the end of the plate with near $100 \%$ skin friction drag reduction.

Drag reduction is also an important phenomenon in cavitation. Wang [11,12] et al. and Ji [13] studied ventilated cavitation. They analyzed the flow field and drag reduction in cavitation. Ceccio [14] reviewed the use of partial cavity, super cavities and gas-injection for drag reduction of axisymmetric objects moving within a liquid. At issue are the conditions under which a stable gas or bubbly layer can be formed through the injection of gas at the surface, the amount of drag reduction that can be achieved,

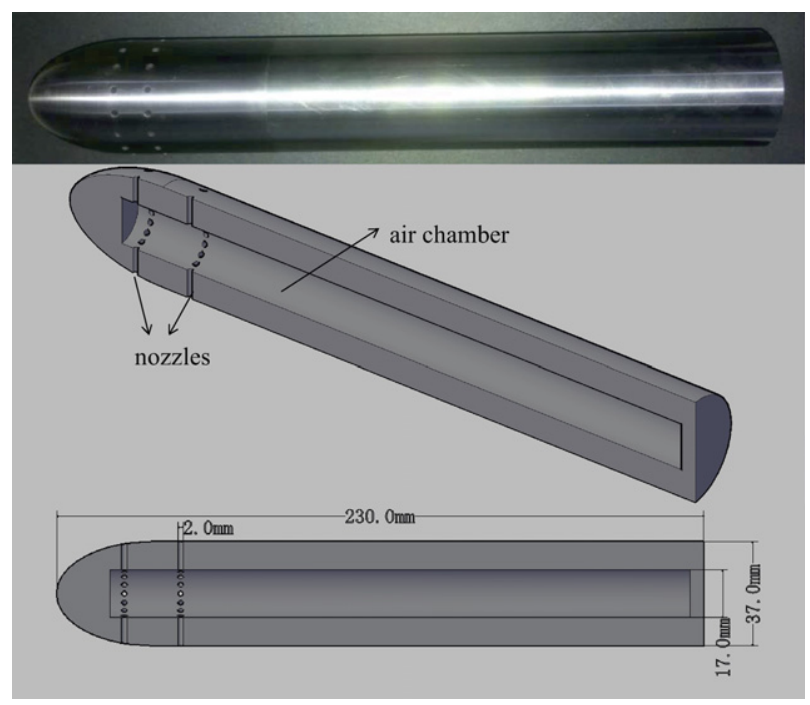

Fig. 2. Experimental model.

the required volume flux, and the possible increase in form (or other components) of drag resulting from the gas injection that might outweigh the benefits of the gas-induced skin-friction drag reduction.

Much development on drag reduction of underwater vehicle has been achieved and this technique has been in application in some countries. But this phenomenon is still an open issue. In present paper, air layer drag reduction of streamlined axisymmetric body is studied by both experiment and numerical simulation. Through analysis of result, mechanism of air layer drag reduction and unsteady evolution of drag are detected.

\section{Experiment}

\subsection{Experiment setup}

Stress wave propagation techniques and SHPB are used in the experiment, as shown in Fig. 1. The scaled underwater launch system mainly consists of three parts, launching system, water tank and high-speed camera. The launching system converted from SHPB is used to accelerate the incident bar.

One-dimensional stress wave theory is employed here to analysis the process of the energy transmission in the system. Details can be got in Ref. [15]. By the stress wave generated from SHPB, the experimental system can accelerate model transiently to $30 \mathrm{~m} / \mathrm{s}$ in less than $200 \mu \mathrm{s}$ with slight disturbance of water during 


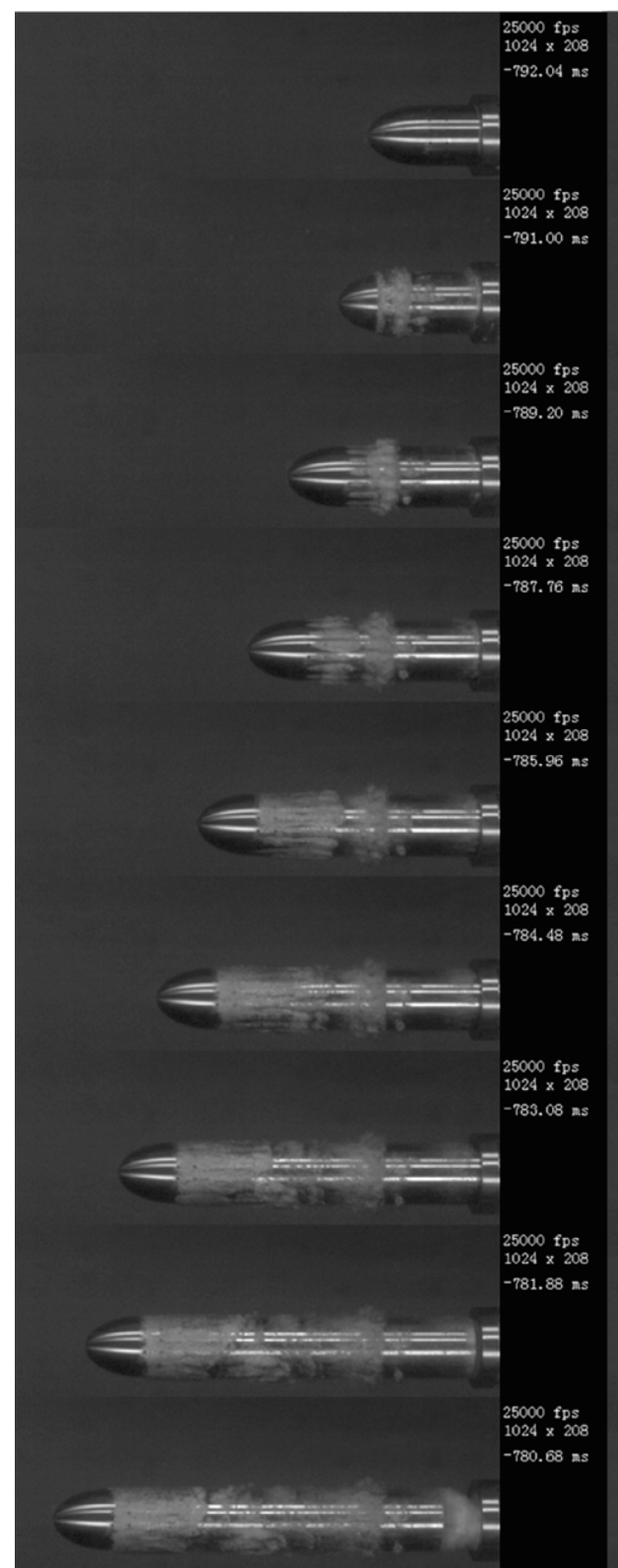

$\mathrm{A}-17.6 \mathrm{~m} / \mathrm{s}$

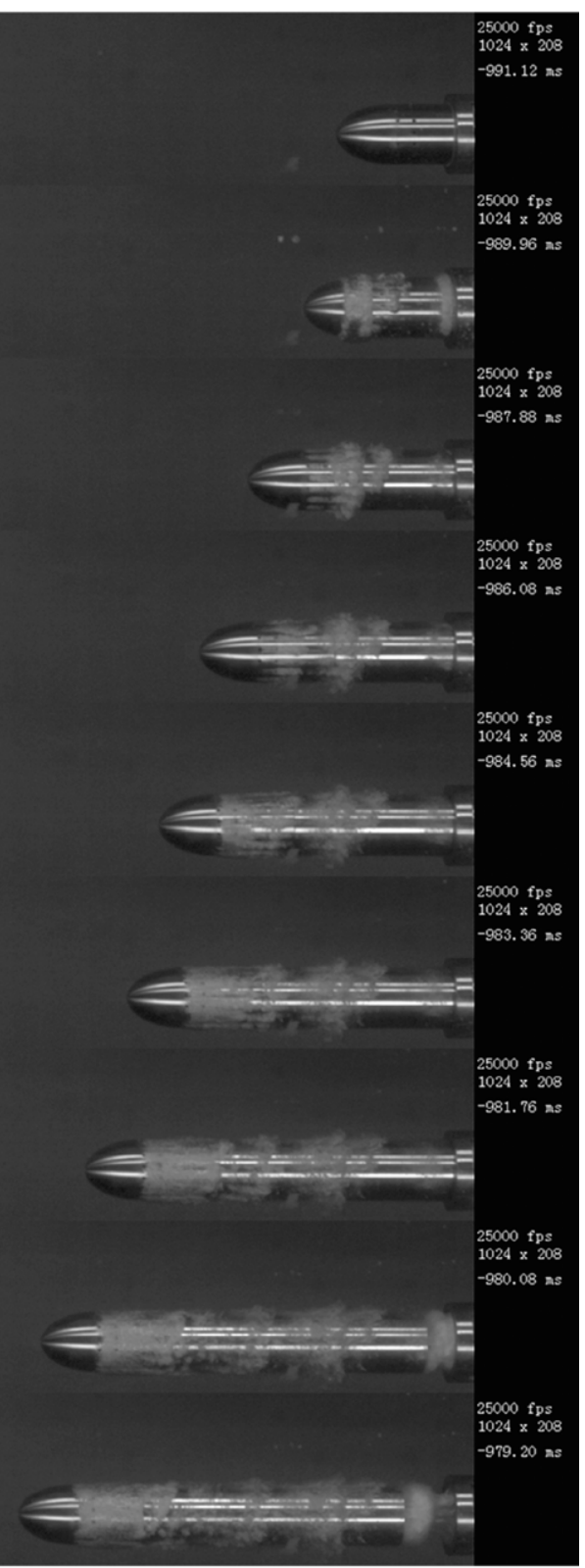

$\mathrm{B}-18.0 \mathrm{~m} / \mathrm{s}$

Fig. 3. Development of air layer in experiment:A-17.6 m/s; B-18.0 m/s.

the whole process. A high speed digital camera was used to record the launch process with a frame grabbing speed of 25000 frames per second.

\subsection{Experiment model}

As shown in Fig. 2, the experimental model is a $230 \mathrm{~mm}$ hollow cylinder with elliptical head. Long axis of the elliptical head is $88 \mathrm{~mm}$ and short axis (i.e. diameter of the cylinder) $37 \mathrm{~mm}$. There are two rows of nozzles at the head. The number of nozzles at every row is 16 with diameter $2 \mathrm{~mm}$. These nozzles are connected with air chamber in the cylindrical body. A cylindrical ring whose outer diameter is $17 \mathrm{~mm}$ and inner diameter $13 \mathrm{~mm}$ can move freely in the air chamber. Before launching, the model is placed on the holder in the water tank. The cylindrical ring is located at the nozzles and seals them. When the model is accelerated transiently, the ring keeps still due to inertance. Thus the air chamber and outside water field are connected through these nozzles. Air in the chamber can be injected into water, as shown in Fig. 3.

\subsection{Experiment results of air layer development}

Our experiment was taken at normal temperature and pressure. The temperature is $20^{\circ} \mathrm{C}$. The projectile is accelerated to $17.6 \mathrm{~m} / \mathrm{s}$ and $18.0 \mathrm{~m} / \mathrm{s}$, as shown in Fig. 3-(A)/(B). Process of the projectile moving in the tank is recorded by high speed camera system. The air injection and air layer are distinct. Fig. 4 shows the length of air layer in the two cases. From Figs. 3 and 4, we can see that air layer evolution in the two cases was very similar because of similar velocity. We take the case of $18 \mathrm{~m} / \mathrm{s}$ in following analysis. The projectile is thought to sailing in uniform speed during this short time. After the projectile is launched, some bubbles appear around the head of the projectile because of shock wave. Pressure of outer field near the nozzles is much lower than that in the air chamber. Thus air will be injected into water field due to pressure differential. Just after air injected, single rows of air develop after every nozzle. With air injection, these air rows connect with each other as a whole and form air layer. The whole air layer increases with time while the tail part broken into fragments. 


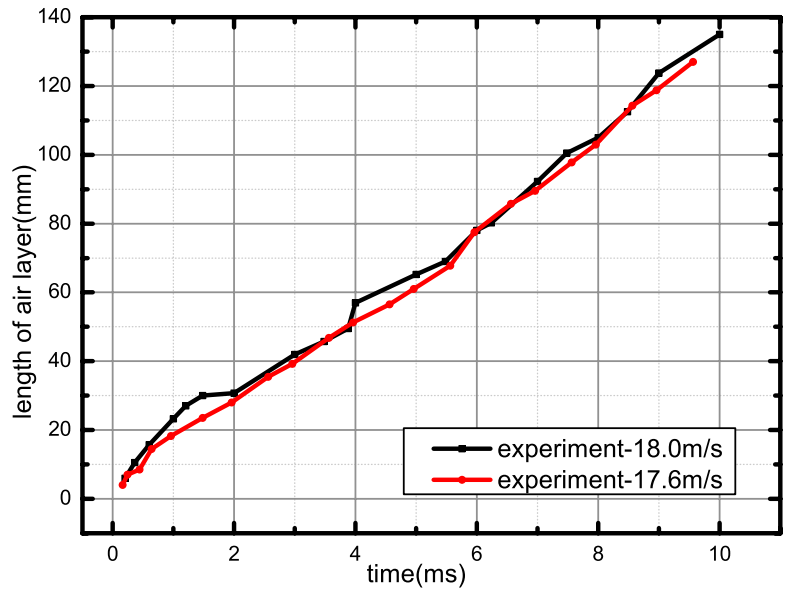

Fig. 4. Length of air layer in two cases $(17.6 \mathrm{~m} / \mathrm{s}$ and $18.0 \mathrm{~m} / \mathrm{s})$.

\section{Numerical simulation}

\subsection{Governing equations}

Two phases, liquid and air, both exist in the field. Implicit VOF method is used in simulation. The VOF method can model two or more immiscible fluids by solving a single set of momentum equations and tracking the volume fraction of each of the fluids throughout the domain. $\alpha$ stands for the volume fraction of water. Governing equations are as follows.

Continuity equation,

$\frac{\partial}{\partial t}\left(\rho_{m}\right)+\nabla \bullet\left(\rho_{m} \vec{v}_{m}\right)=0$

where $\rho_{m}=\alpha_{l} \rho_{l}+\alpha_{g} \rho_{g}$ is the mixture density and $\vec{v}_{m}=$ $\frac{\alpha_{l} \rho_{l} \vec{v}_{l}+\alpha_{g} \rho_{g} \vec{v}_{g}}{\rho_{m}}$ is the mixture's velocity. Subscript $l$ and $g$ stand for liquid and air respectively, satisfying $\alpha_{1}+\alpha_{g}=1$.
Momentum equation,

$$
\begin{aligned}
& \frac{\partial}{\partial t}\left(\rho_{m} \vec{v}_{m}\right)+\nabla \bullet\left(\rho_{m} \vec{v}_{m} \vec{v}_{m}\right) \\
& \quad=-\nabla p+\nabla\left[\mu_{m}\left(\nabla \vec{v}_{m}+\nabla \vec{v}_{m}^{T}\right)\right]+\rho_{m} \vec{g}+\vec{F} k k
\end{aligned}
$$

where $\mu_{m}=\alpha_{l} \mu_{l}+\alpha_{g} \mu_{g}$ is viscosity of mixture, $\vec{F}$ is body force.

Energy equation,

$\frac{\partial}{\partial t}\left(\rho_{m} E\right)+\nabla \bullet\left[\vec{v}\left(\rho_{m} E+p\right)\right]=\vec{v}_{k}\left(k_{e f f} \nabla T\right)+S_{E}$

where $k_{\text {eff }}$ is effective thermal conductivity and $S_{E}$ is source term. The VOF model treats energy, $E$, and temperature, $T$, as mass averaged variables. $E=\frac{\alpha_{l} \rho_{l} E_{l}+\alpha_{g} \rho_{g} E_{g}}{\alpha_{l} \rho_{l}+\alpha_{g} \rho_{g}}$ where $E_{l}$ and $E_{g}$ for liquid and gas is based on the shared temperature and the specific heat of that phase.

Water transport equation,

$\frac{\partial \alpha_{l}}{\partial t}+\nabla \bullet\left(\overline{\vec{v}} \alpha_{l}\right)=0$

\subsection{Turbulent model}

We adopt RNG $k-\varepsilon$ model to solve transport equation about turbulent kinetic energy and dissipation rate. The viscosity in original RNG model is much larger than real viscosity in mixture area, inducing excessive dissipation. According to Dular [16] and Reboud [17], modified viscosity function is adopted in RNG $k-\varepsilon$ model.

$\left\{\begin{array}{l}\mu_{t}=f(\rho) C_{\mu} \frac{k^{2}}{\varepsilon} \\ f(\rho)=\rho_{v}+\frac{\left(\rho_{m}-\rho_{v}\right)^{n}}{\left(\rho_{l}-\rho_{v}\right)^{n-1}} \quad n \gg 1 .\end{array}\right.$

According Coutier-Delgosha [18], $n=10$ here.

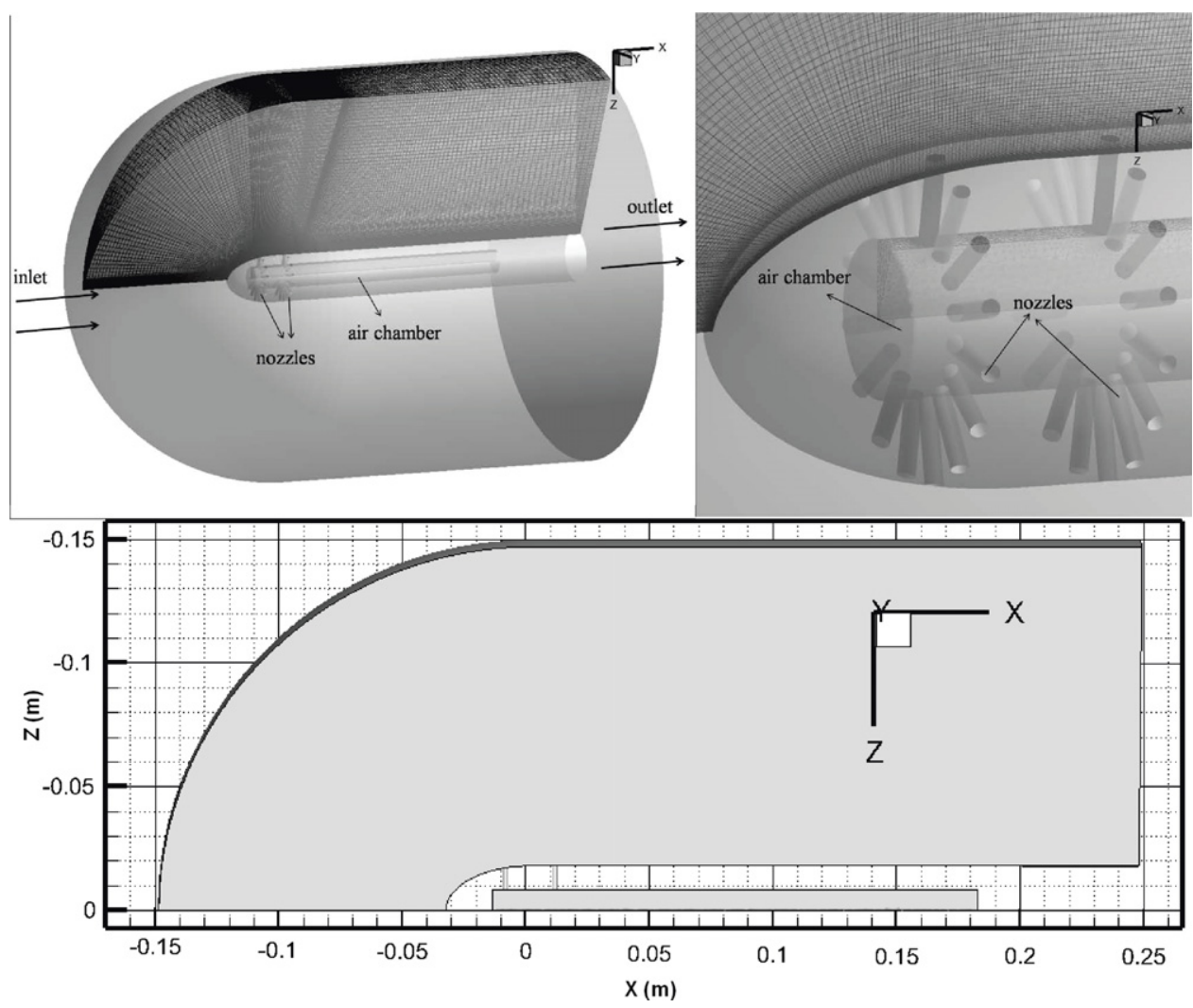

Fig. 5. The computational model. 


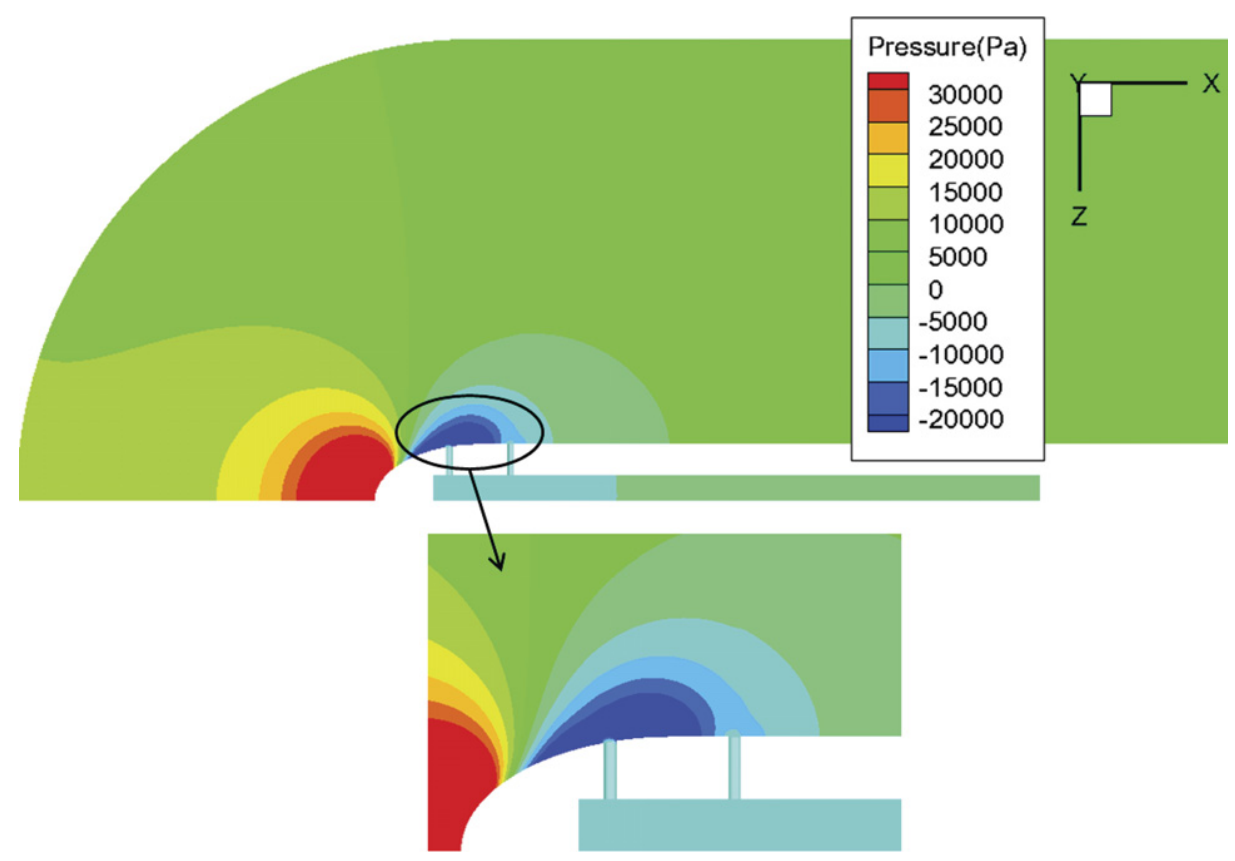

Fig. 6. Pressure field at the beginning of air injecting in simulation.

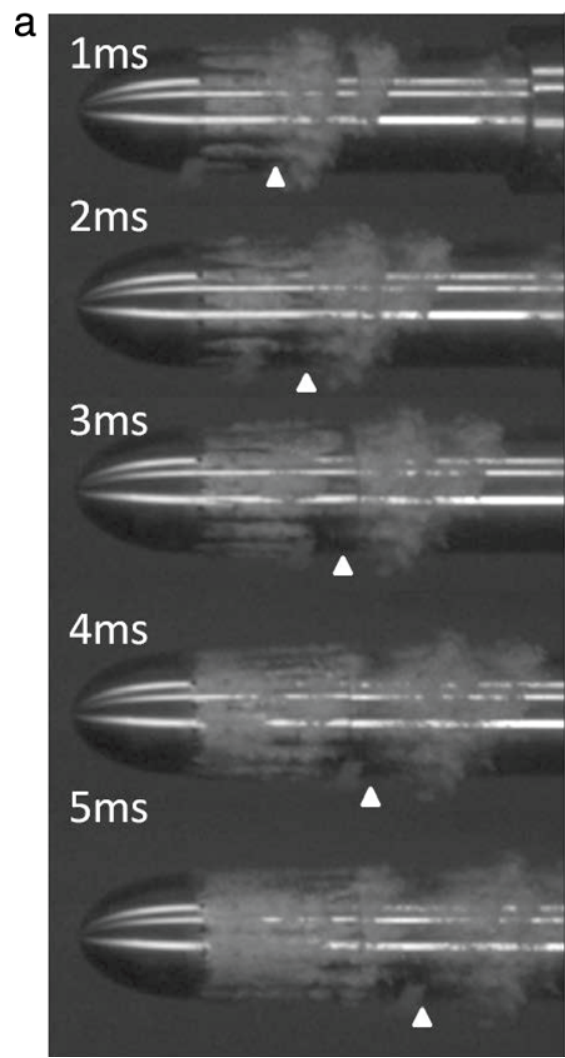

\section{$\mathrm{b}$}

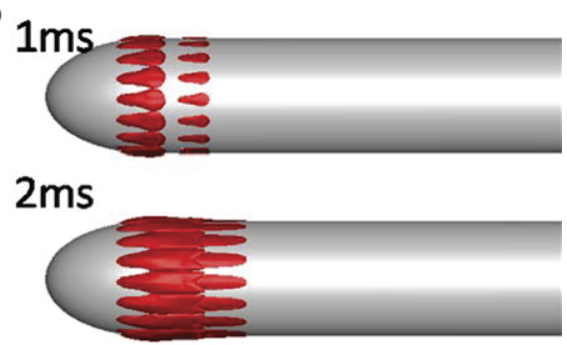

$3 \mathrm{~ms}$

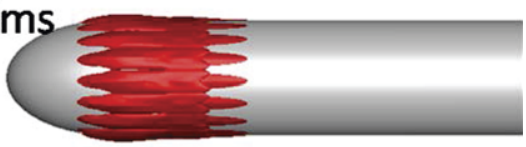

$4 \mathrm{~ms}$

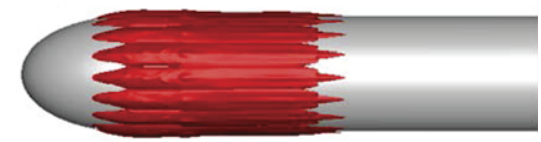

$5 \mathrm{~ms}$

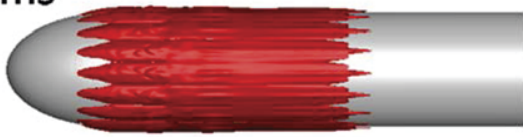

Fig. 7. Development of air layer in (a) experiment and (b) simulation.

\subsection{Simulation}

Considering the circumferential development of air layer, 3D simulation model is adopted. Fig. 5 shows computational model with structured mesh in outer field and unstructured mesh in air chamber. Corresponding to experimental model, diameter of the model is $37 \mathrm{~mm}$ and that of nozzles is $2 \mathrm{~mm}$. Diameter of outer field is $200 \mathrm{~mm}$. The projectile is axisymmetric with 16 nozzles.
Taking computational efficiency into account, $1 / 16$ of the model is employed in simulation with 2 million grids.

It is ideal gas in air chamber and water in outer field. Operate pressure is $1 \mathrm{~atm}$. Velocity of inlet is $18.0 \mathrm{~m} / \mathrm{s}$ and pressure of outlet is $0 \mathrm{~Pa}$ (Unless stated, pressure in the paper refers to gauge pressure). SIMPLEC method is used in simulation and time step is set as $10^{-5} \mathrm{~s}$. According to experimental results, it is air layer not bubble that forms on the surface. Thus surface tensor is ignored in simulation. 


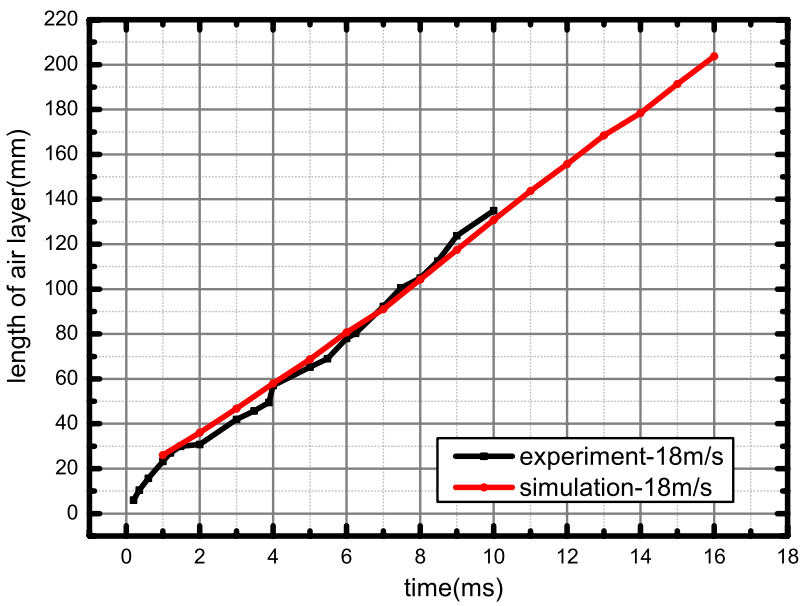

Fig. 8. Length of air layer in experiment and simulation.

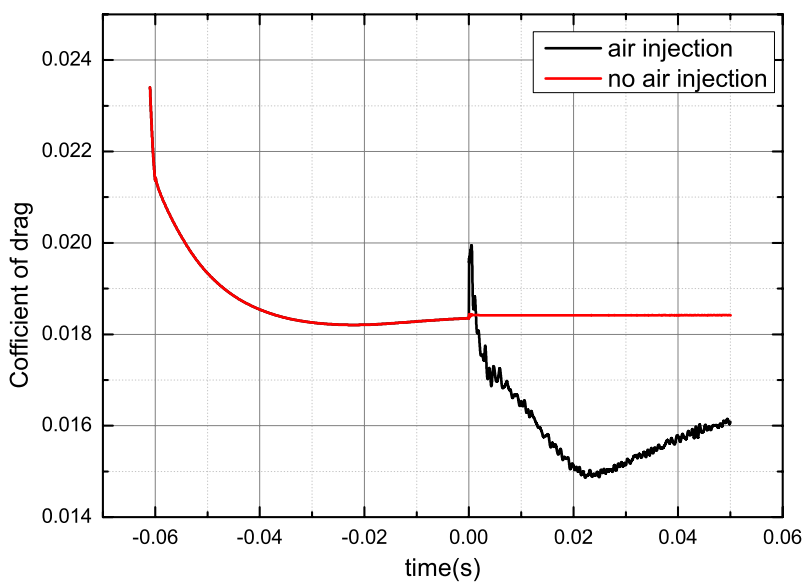

Fig. 9. Evolution of drag coefficient of simulation.

\section{Results}

\subsection{Evolution of air layer}

From simulation, pressure field at air injected is obtained. Pressure of outer field near the nozzles is much lower than that of air chamber, as shown in Fig. 6. Thus air will be injected into water field due to pressure differential. Fig. 7 shows development of air layer in first $5 \mathrm{~ms}$ after air injection. Obvious air injection can be observed in both experiment and simulation. Injected air flows closely on model's surface and turns into air layer. The air layer length could be measured through experimental and computational images. For example, the length of the cylinder is $240 \mathrm{~mm}$ corresponding to 321 pixels in experimental pictures. Then 1 pixel stands for $0.75 \mathrm{~mm}$ in experiment. Fig. 8 shows length of air layer by measuring its pixels. It can be seen that length of air layer increases gradually in both experiment and simulation. Length in simulation is slightly longer than that in experiment. From the above, the simulation results are consistent with experiment, which indicates that the dominated physical mechanisms are being modeled in the numerical simulation.

\subsection{Mechanism of drag reduction}

In order to study the effect of air layer on drag reduction, ventilated and single phase cases are both considered in this paper. Fig. 9 shows drag coefficient of two cases. The moment when air begins to inject is set as $0 \mathrm{~ms}$. We can get that drag decreases about $22 \%$ after air injecting. Air layer is an effective drag reduction method.

Analysis on mechanism of air layer drag reduction is taken. After air injection, distribution of air varies with positions on the surface of the projectile, as shown in Fig. 10. At the locations near the nozzles, volume fraction of air is very high, as area A in Fig. 10. Fluid is heterogeneous here. Mechanism of drag reduction is based on the basic shear stress equation for fluid. At positions far from the nozzles, air and water mix uniformly, as B in Fig. 10. Fluid

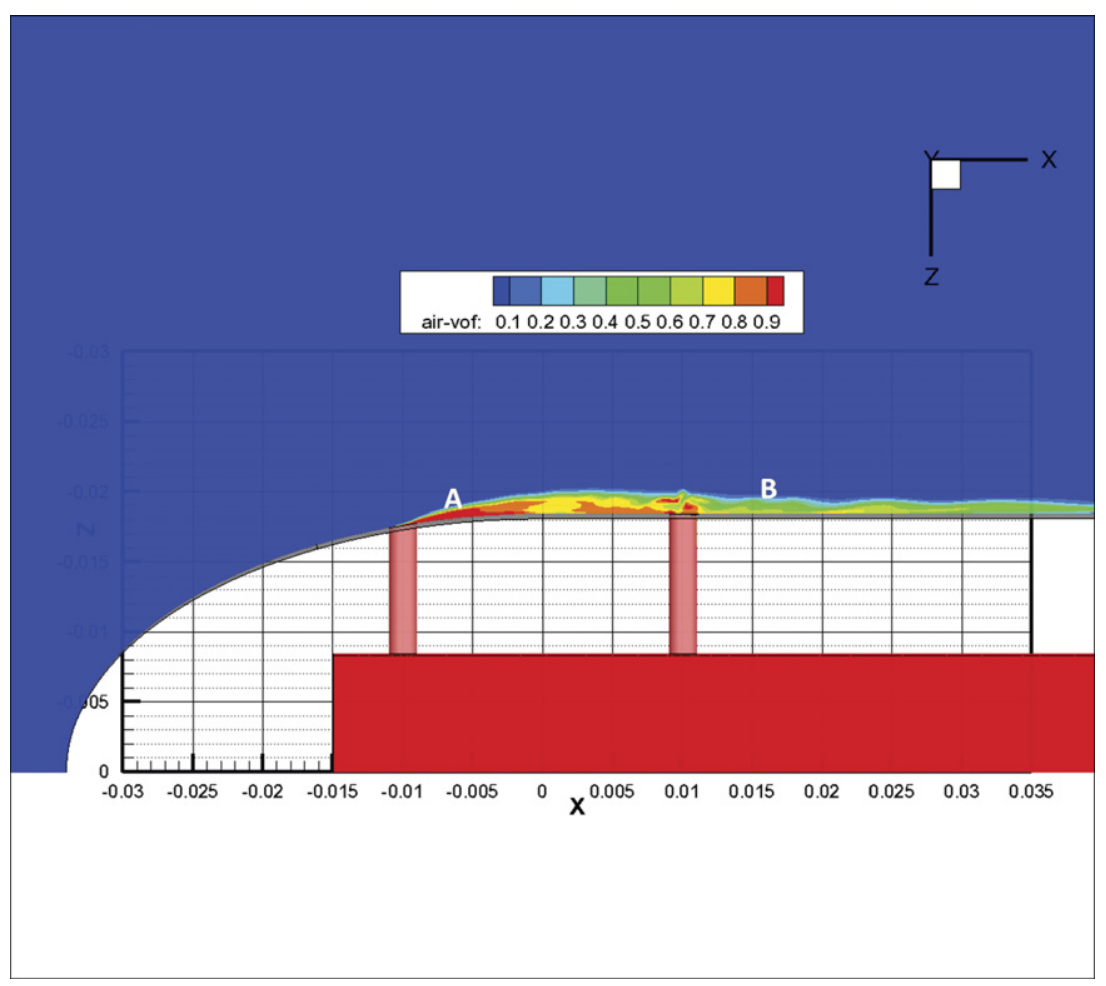

Fig. 10. Air volume fraction near the surface of the projectile at $t=4 \mathrm{~ms}$ in simulation. 


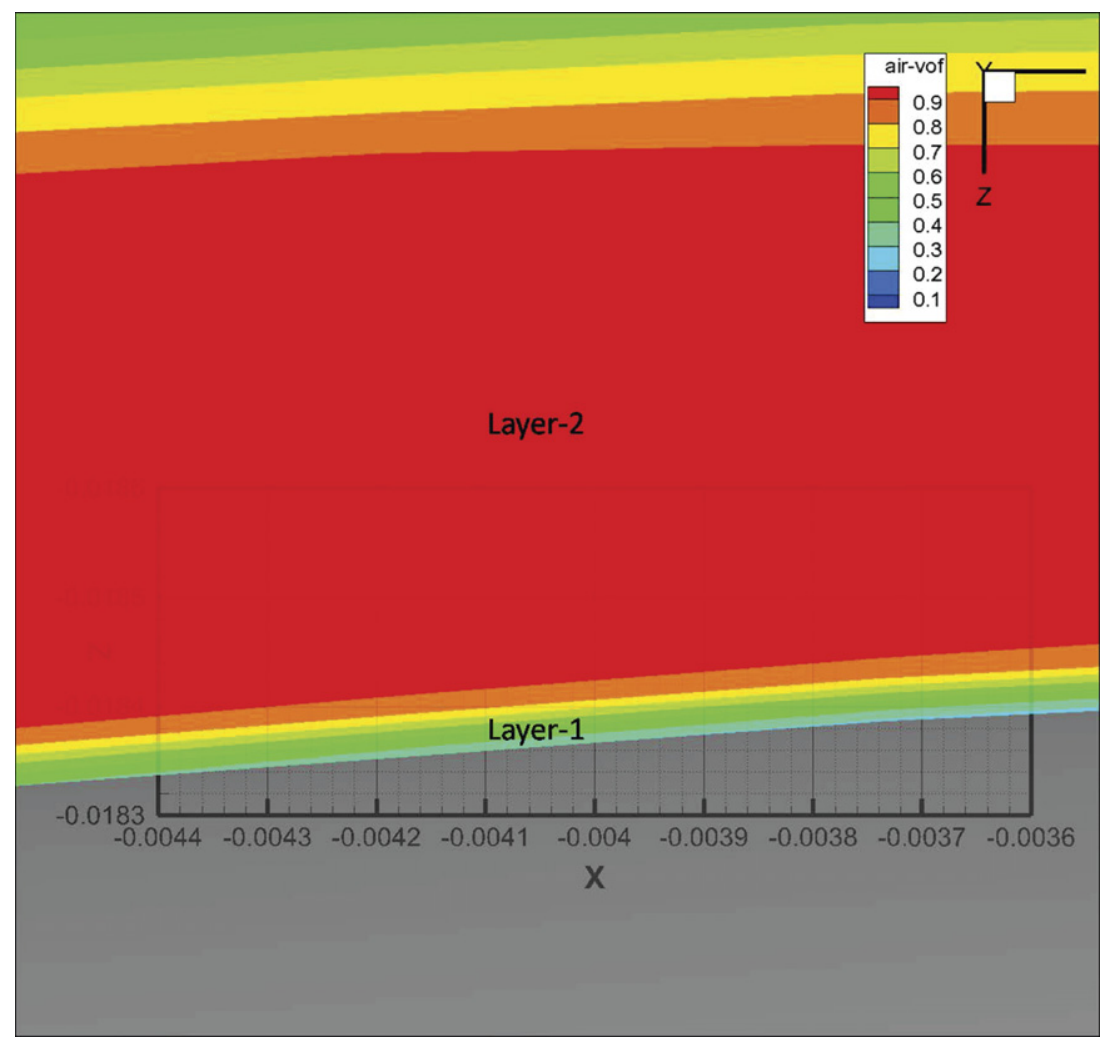

Fig. 11. Air volume fraction at area $\mathrm{A}$ when $t=4 \mathrm{~ms}$ in simulation.

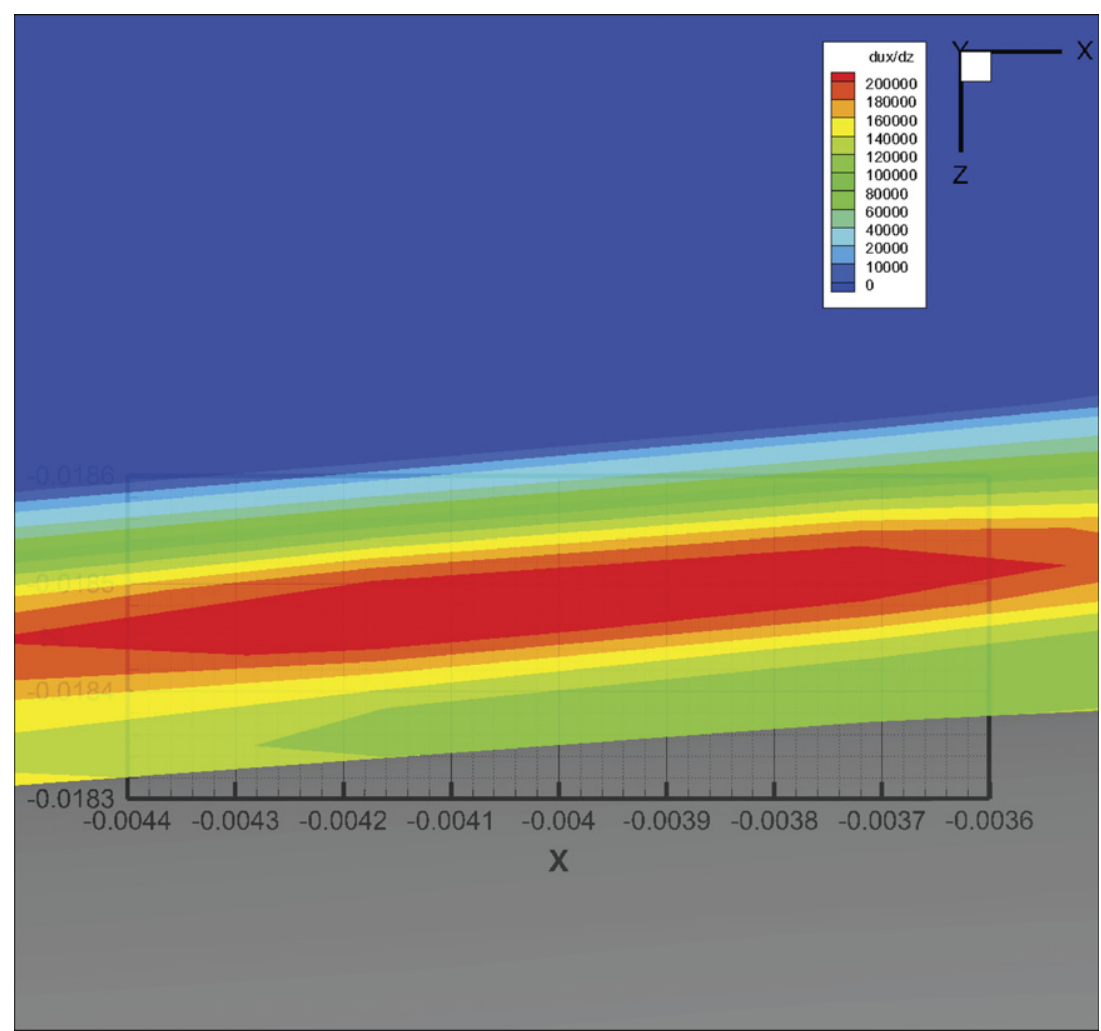

Fig. 12. Velocity gradient after air injection at area A when $t=4 \mathrm{~ms}$ in simulation. 


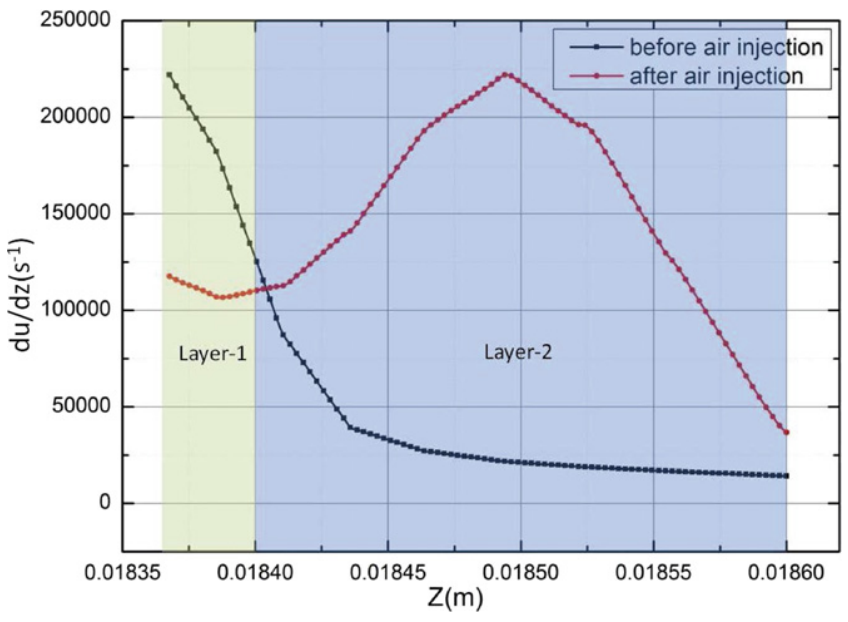

Fig. 13. Velocity gradient at $x=-0.004 \mathrm{~m}$ before and after air injection in simulation.

is thought to be homogeneous. Empirical equation of turbulent boundary layer shear stress can be applied here. Details of drag reduction mechanism are as follows.

(1): Area near nozzles with obvious air layer (such as A in Fig. 10). Fig. 11 shows contour of air volume fraction at area $A$ in Fig. 10. We can see that liquid in boundary layer at $A$ is heterogeneous and layered. Layer 1 , which is close to the wall, is very thin and has much water. Layer 2, outside Layer 1, contains more than $98 \%$ air. This layer can be supposed to be an air layer. Empirical equation of homogeneous turbulent boundary layer is no longer suitable here. Therefore the basic equation for shear stress in fluid mechanics is adopted.

$\tau_{w}=\mu\left(\frac{\partial u}{\partial z}\right)_{z=0}$ where $\left(\frac{\partial u}{\partial z}\right)_{z=0}$ is velocity gradient at the wall and $\mu$ is dynamic viscosity of the mixture. In classic boundary layer theory, velocity gradient $\left(\frac{\partial u}{\partial z}\right)_{z=0}$, which is very large, contributes a lot to friction drag for underwater projectile.

Fig. 12 shows velocity gradient $\frac{\partial u}{\partial z}$ at $\mathrm{A}$ at $t=4.0 \mathrm{~ms}$ (the moment air begin to inject is set as $t=0$ ). Curves in Fig. 13 shows $\frac{\partial u}{\partial z}$ at $x=-0.004$ when $t=0$ and $t=4 \mathrm{~ms}$. Before air injection, maximum $\frac{\partial u}{\partial z}$ locates at $z=0$ as the black curve shows, and the value of $\frac{\partial u}{\partial z}$ decreases monotonically along the line vertical to the wall. After air injection, $\left(\frac{\partial u}{\partial z}\right)_{z=0}$ reduces significantly, which is much smaller than that before air injection. Maximum of velocity gradient transfers from Layer 1 to the air layer, as the red curve shows. On the other hand, liquid in Layer 1 is mixture of air and water although fraction of air is only about $30 \%$. $\mu$ at $z=0$ decreases after air injection too.

According to Eq. (6), shear stress $\tau_{w}$ at areas near the nozzles will reduce as $\mu$ and $\left(\frac{\partial u}{\partial z}\right)_{z=0}$ decreases.

(2): Area which is far from the nozzles (such as B in Fig. 10). At $B$, air and water mix uniformly near the wall, as shown in Fig. 14. The mixture is homogeneous. In boundary layer of the mixture, distribution of velocity gradient along the normal of the wall is the same with that before air injection, as shown in Fig. 15. Empirical equation of turbulent boundary layer shear stress for homogeneous fluid could be applied here.

$\tau_{w}=0.0225 \rho U_{\infty}^{2}\left(\frac{v}{U_{\infty} \delta}\right)^{\frac{1}{4}}$

where $\delta$ stands for thickness of boundary layer. Substituting $\delta=$ $0.37 x \operatorname{Re}_{x}^{-\frac{1}{5}}$ and $\operatorname{Re}_{x}=\frac{U_{\infty} x}{v}$ into Eq. (7), we can get

$\tau_{w}=0.0225 \rho U_{\infty}^{\frac{9}{5}}\left(\frac{v}{x}\right)^{\frac{1}{5}}$

where $\rho$ is the mixture density, $U_{\infty}$ is inflow velocity, $v$ is kinematic viscosity of mixture and $x$ is abscissa on the surface of

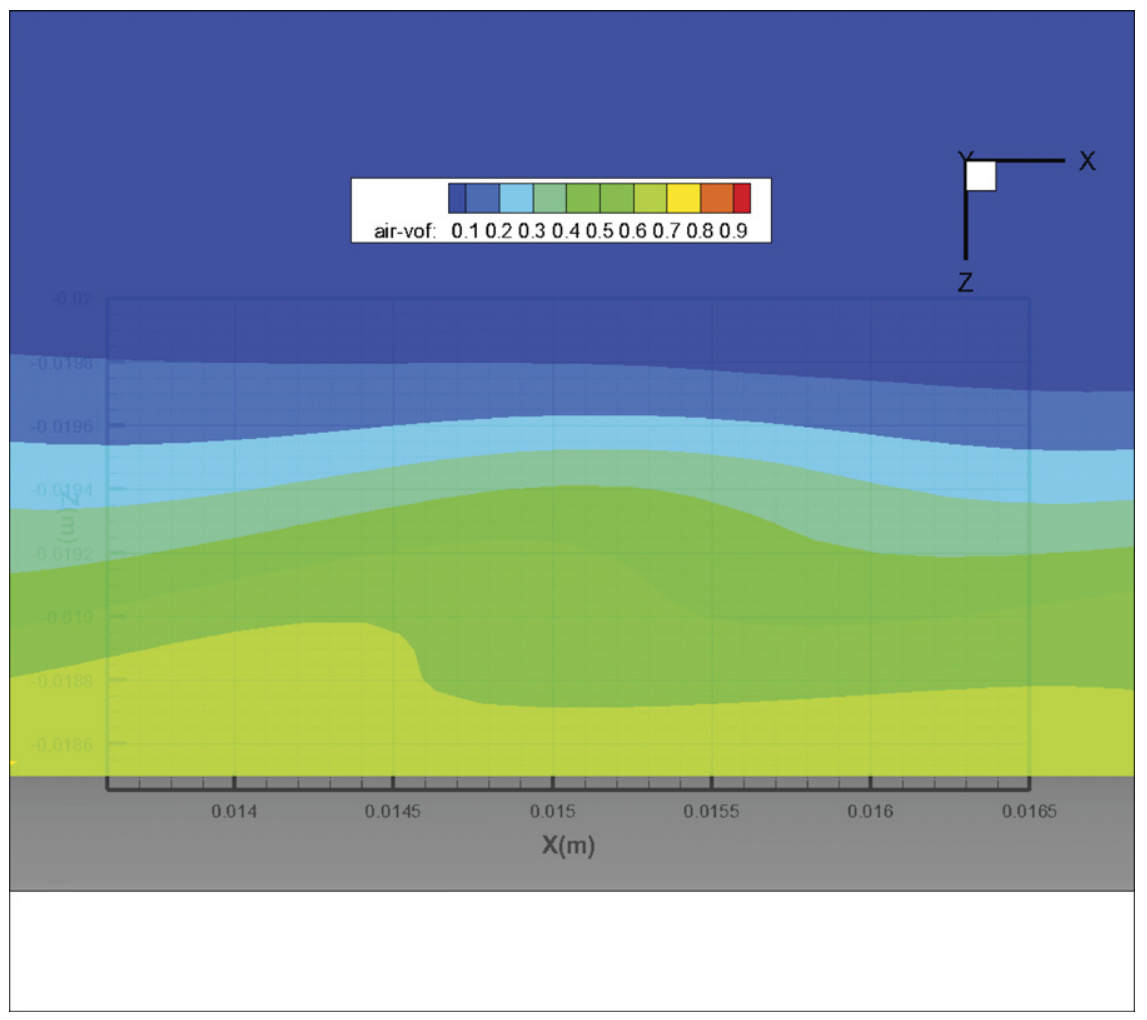

Fig. 14. Air volume fraction at area $\mathrm{B}$ when $t=4 \mathrm{~ms}$ in simulation. 


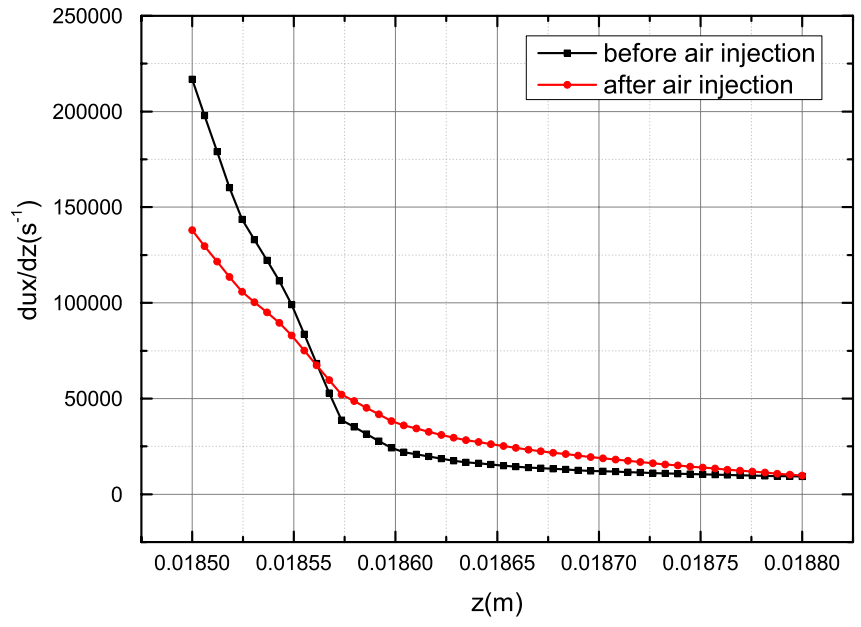

Fig. 15. Velocity gradient at $x=0.015 \mathrm{~m}$ before and after air injection when $t=4 \mathrm{~ms}$ in simulation.

projectile. When $U_{\infty}$ and $x$ are fixed, shear stress is only related with $\rho$ and $v^{\frac{1}{5}}$. A function $f$ is defined as follows,

$f=\frac{\rho v^{\frac{1}{5}}}{\rho_{l} v_{l}^{\frac{1}{5}}}$

$f$ denotes the ratio of shear stress between after and before air injection at the same location on the projectile surface. According to the assumption of VOF method, when volume fraction of air is $\alpha$ and water $(1-\alpha)$, density of mixture is $\rho=\rho_{g} \alpha+\rho_{l}(1-\alpha)$, and dynamic viscosity $\mu=\mu_{g} \alpha+\mu_{l}(1-\alpha)$. Then kinematic viscosity can be calculated as $v=\frac{\mu_{g} \alpha+\mu_{l}(1-\alpha)}{\rho_{g} \alpha+\rho_{l}(1-\alpha)}$. Therefore curve of $f-\alpha$ is obtained, as shown in Fig. 16. From the curve, for arbitrary air volume fraction $\alpha, f$ is less than 1 . It indicates that viscous drag after air injection is always smaller than that in pure water.

After air injection, density and kinematic viscosity of mixture are both changed. The former decreases while the latter increases. $f_{1}(\alpha)=\frac{\rho}{\rho_{l}}$ shows density ratio of mixture to pure water. $f_{2}(\alpha)=$ $\frac{v^{\frac{1}{5}}}{v_{1}^{\frac{1}{5}}}$ stands for kinematic viscosity ratio of mixture to pure water. Figs. 17, 18 show changes of $f_{1}, f_{2}$ with air volume fraction $x$. Mixture density after air injection decreases linearly and fast with increase of $\alpha$. Kinematic viscosity of mixture is approximate to that of pure water when $\alpha<0.95$. Then drag of projectile is reduced mostly because of rapid drop of density. When air volume fraction $\alpha>0.95$, kinematic viscosity increases rapidly. However, high air volume fraction also leads to mixture density very near to air. Effect of density decrease on drag fraction is much larger than that of kinematic viscosity decrease. As result, drag fraction of projectile is still reduced.

To sum up, air injection may reduce drag of high speed underwater projectile effectively.

\subsection{Unsteady evolution of drag force}

From Fig. 9, one can also get that drag of the projectile decreases fast at first and then increases slightly with air injection. Fig. 19 shows air volume fraction along normal direction at $x=0$ as air injecting. Over time, air fraction and air layer thickness decrease obviously around the wall. Taking Figs. 8/15 into analysis, it can be got that air layer drag reduction is related with both length and thickness of air layer. At initial stage of air injection, length of air layer is in the leading role. Area of drag reduction increases as air

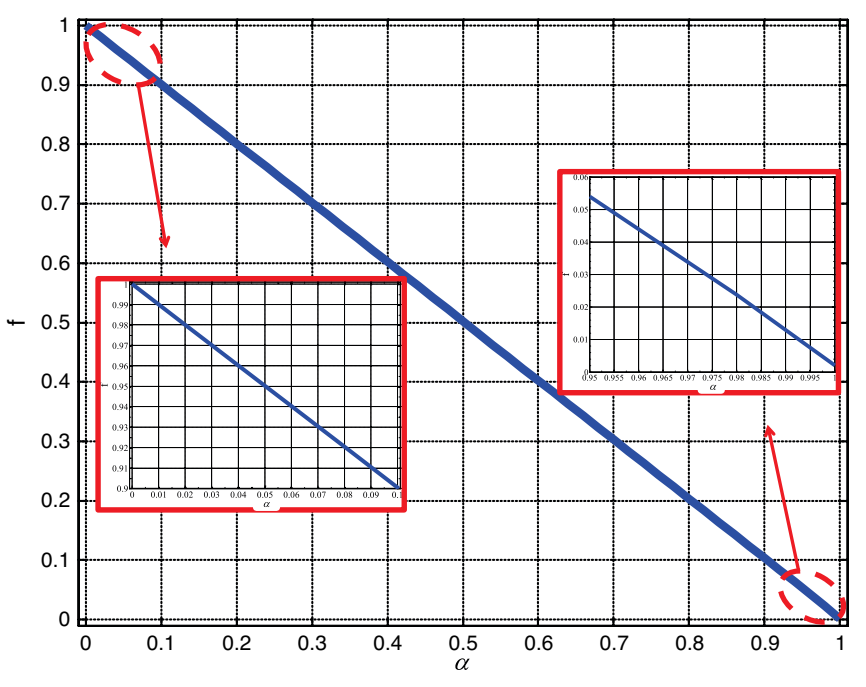

Fig. 16. The curve of $f$ at different $\alpha$ from simulation.

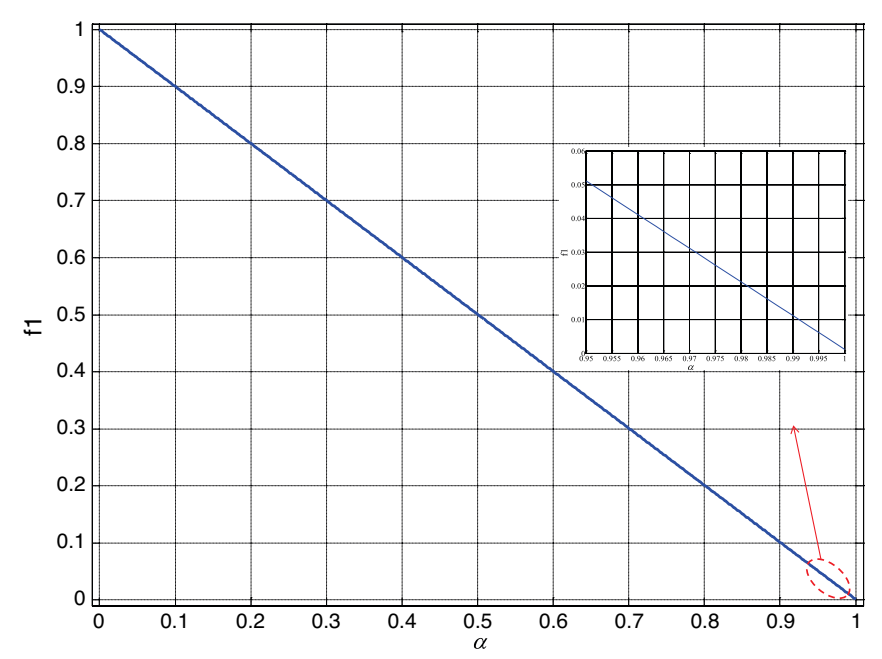

Fig. 17. The curve of $f_{1}$ at different $\alpha$ from simulation.

layer length grows. However, air in the boundary layer reduces with air injection, shown in Fig. 19. Fig. 20 shows pressure field around nozzles at $25 \mathrm{~ms}$ after air injection. At nozzles B, outer pressure has been higher than that of inner chamber. Air has been unable to inject from chamber into outer field. Air in boundary layer reduced as a result. The thickness of air layer begins to affect drag reduction, leading slight rise of drag force.

\section{Conclusion}

In summary, experiment and simulation been performed in present paper to study the effect and mechanism of air layer drag reduction. Simulation result is consistent with experiment, which verifies reasonability of simulation. Through result analysis, drag of model can be reduced by $25 \%$. Air injection into boundary, which can reduce density, viscosity and velocity gradient at the bottom of the boundary layer, is an effective method to reduce drag. As the projectile moves, drag decreases fast at first and then increases slightly. Both length and thickness of air layer affect the amount of air reduction.

Also it is need to take further research on air layer drag reduction, such as dimensional analysis of this phenomenon, effect of different air amount, influence of incoming velocity, etc. 


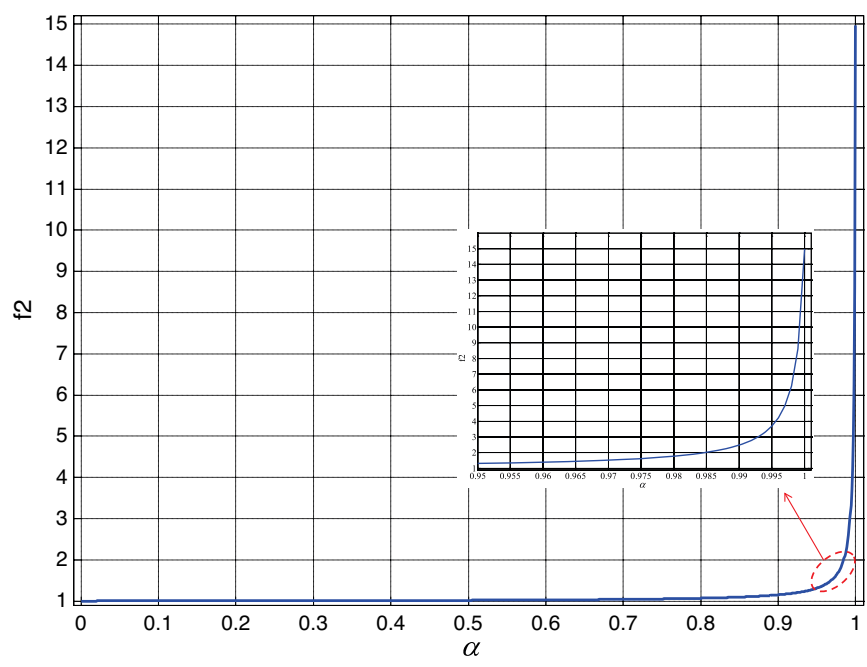

Fig. 18. The curve of $f_{2}$ at different $\alpha$ from simulation.

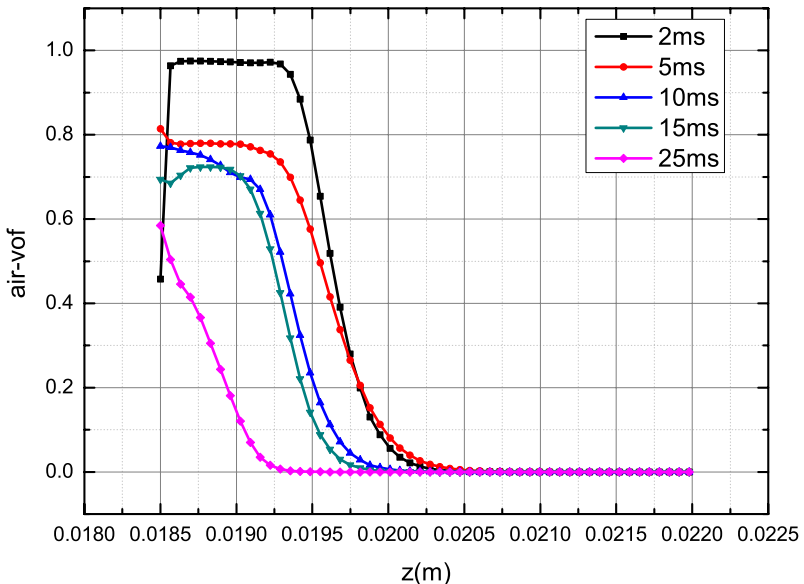

Fig. 19. Air volume fraction along normal direction with time of air injecting $(x=0)$ in simulation.

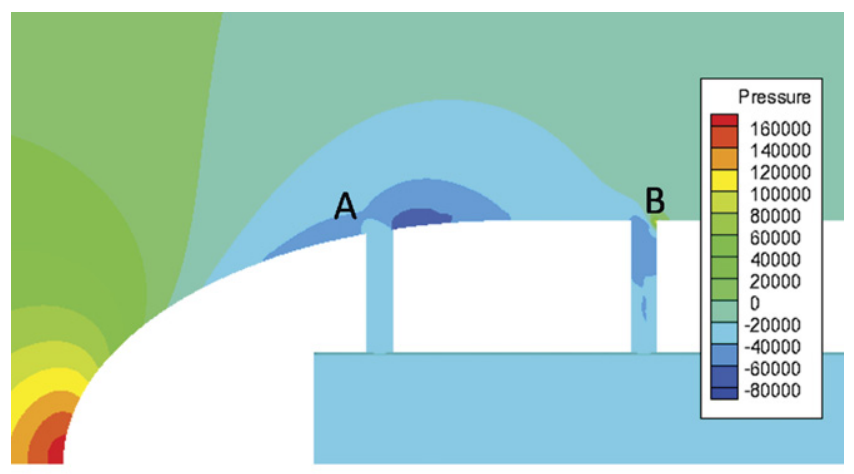

Fig. 20. Pressure field around nozzles at $25 \mathrm{~ms}$ of air injecting in simulation.

\section{Acknowledgment}

This research was sponsored by National Natural Science Foundation of China under Contract 11332011 (Chenguang Huang, Program Manager) and 11202215 (Yiwei Wang, Program Manager).

\section{References}

[1] B.R. Elbing, S. Mäkiharju, A. Wiggins, M. Perlin, R.D. Dowling, On the scaling of air layer drag reduction, J. Fluid Mech. 717 (2013) 484-513.

[2] M.E. McCormick, R. Bhattacharyya, Drag reduction of a submersible hull by electrolysis, Nav. Eng. J. 85 (1973) 11-16.

[3] C.L. Merkle, S. Deutsch, Microbubble drag reduction in liquid turbulent boundary layers, Appl. Mech. Rev. 45 (1992) 103-127.

[4] N.K. Madavan, S. Deutsch, C.L. Merkle, Reduction of turbulent skin friction by microbubbles, Pennsylvania State University Park Applied Research Lab. 1983.

[5] N.K. Madavan, S. Deutsch, C.L. Merkle, Numerical investigations into the mechanisms of microbubble drag reduction, J. Fluids Eng.-Trans. ASME 107 (1985) 370-377.

[6] B.R. Elbing, E.S. Winkel, K.A. Lay, S.L. Ceccio, D.R. Dowling, M. Perlin, Bubbleinduced skin-friction drag reduction and the abrupt transition to air-layer drag reduction, J. Fluid Mech. 612 (2008) 201-236.

[7] S.A. Mäkiharju, B.R. Elbing, A. Wiggins, S. Schinast, J.M. Vanden-Broeck, M. Perlin, S.L. Ceccion, On the scaling of air entrainment from a ventilated partial cavity, J. Fluid Mech. 732 (2013) 47-76.

[8] E.S. Winkel, B.R. Elbing, S.L. CeccioL, M. Perlin, D.R. Dowling, Bubble friction drag reduction in a high-Reynolds-number flat-plate turbulent boundary layer, J. Acoust. Soc. Am. 123 (2008) 2522-2530.

[9] J. Xu, M.R. Maxey, G.E. Karniadakis, Numerical simulation of turbulent drag reduction using micro-bubbles, J. Fluid Mech. 468 (2002) 271-281.

[10] W.C. Sanders, E.S. Winkel, D.R. Dowling, M. Perling, S.L. Ceccio, Bubble friction drag reduction in a high-Reynolds-number flat-plate turbulent boundary layer, J. Fluid Mech. 552 (2006) 353-380.

[11] Y.W. Wang, C.G. Huang, T.Z. Du, X.O. Wu, X. Fang, Shedding phenomenon of ventilated partial cavitation around an underwater projectile, Chin. Phys. Lett. 29 (2012) 014601.

[12] X.X. Yu, Y.W. Wang, C.G. Huang, T.Z. Du, Unsteady characteristics of ventilated cloud cavit around symmetrical bodies, J. Ship Mech. 5 (2014) 499-506. (in Chinese).

[13] B. Ji, X.W. Luo, X.X. Peng, Y. Zhang, Y.L. Wu, H.Y. Xu, Numerical investigation of the ventilated cavitating flow around an under-water vehicle based on a threecomponent cavitation model, J. Hydrodyn., Ser. B 22 (6) (2010) 753-759.

[14] S.L. Ceccio, Friction drag reduction of external flows with bubble and gas injection, Annu. Rev. Fluid Mech. 42 (2010) 183-203.

[15] Y.P. Wei, Y.W. Wang, X. Fang, C.G. Huang, Z.P. Duan, A scaled underwater launch system accomplished by stress wave propagation technique, Chin. Phys. Lett. 28 (2001) 024601.

[16] M. Dular, R. Bachert, B. Stoffel, B. Sirok, Experimental evaluation of numerical simulation of cavitating flow around hydrofoil, Eur. J. Mech. B-Fluids 24 (2005) 522-538.

[17] J.L. Reboud, B. Stutz, O. Coutier, Two-phase flow structure of cavitation: experiment and modeling of unsteady effect, in: Third International Symposium on Cavitation, Grenoble, France, 1998.

[18] O. Coutier-Delgosha, R. Fortes-Patella, J.L. Reboud, Evaluation of turbulence model influence on the numerical simulations on unsteady cavitation, J. Fluids Eng. 125 (2003) 38-45. 